\title{
The Design of Musical Instruments for Grey Parrots: An Artistic Contribution toward Auditory Enrichment in the Context of ACI
}

\author{
Reinhard Gupfinger * and Martin Kaltenbrunner(D) \\ Tangible Music Lab, Institute of Media Studies, University of Art and Design Linz, 4020 Linz, Austria; \\ martin.kaltenbrunner@ufg.at \\ * Correspondence: reinhard.gupfinger@ufg.at
}

Received: 21 February 2020; Accepted: 27 April 2020; Published: 3 May 2020

check for updates

\begin{abstract}
One particular approach in the context of Animal Computer Interaction (ACI) is auditory enrichment for captive wild animals. Here we describe our research and the methodology used to design musical instruments and interfaces aimed at providing auditory enrichment for grey parrots living in captivity. The paper is divided into three main phases: a project review and classification, sonic experiments at the parrot shelter and the design of musical instruments. The overview of recent projects that involve animals in the interaction and music-generation process highlights the costs and benefits of projects of this kind and provides insights into current technologies in this field and the musical talents of animals. Furthermore, we document a series of sonic experiments conducted at a parrot shelter to develop acoustically enriched environments through the use of musical instruments. These investigations were intended to provide a better understanding of how grey parrots communicate through sound, perceive and respond to auditory stimuli and possibly generate sound and music through the usage of technological devices. Based on the cognitive, physiological, and auditory abilities of grey parrots, and their intrinsic interest in sonic and physical interactions, we finally developed and tested various interactive instrument prototypes and here we present our design results for auditory enrichment in the context of ACI and artistic research.
\end{abstract}

Keywords: ACI; auditory enrichment; animal-centered design; artistic research; metamusic

\section{Introduction}

We strongly support the idea that wild animals should not be kept in manmade environments such as zoological gardens, laboratories, animal shelters or even private homes, but if they are forced to, for whatever reasons, we have the particular responsibility to promote adequate and dignified living conditions for each species. The challenges of maintaining wild animals in captivity are broad, and there are several forms of enrichments that can be employed to increase their well-being. In the near future, the use of new technologies that promote species-specific behaviors could lead to significant improvements in many aspects of these artificial habitats.

The still relatively young research discipline of Animal-Computer Interaction (ACI) focuses on developing new technologies for animals from an animal-centered design perspective [1]. One particular approach in the context of ACI is auditory enrichment for captive wild animals. Efforts are being made to improve the artificial habitats of these animals and to prevent them developing behavioral disorders by implementing different forms of auditory enrichment environments and devices. It therefore seems appropriate and promising to test and implement such auditory enrichment technologies for animal species with high auditory abilities and complex sound communication. African grey parrots, 
the research subjects of this project, are, according to the current state of knowledge, considered to be one of the most talented musicians in the animal kingdom.

The artistic research approach adopted in this project intends to make a substantial and experimental contribution towards issues of musicality in the animal kingdom, animal-centered design and the development of technology for the auditory enrichment in the context of ACI.

The concept of music used in this project is understood in a very broad sense and allows animals to generate sounds that go beyond their basic sound communication. This includes sounds that have been created using musical instruments and interfaces designed for the cognitive and physiological abilities of grey parrots. Based on the idea that music has its biological roots in the animal kingdom, we follow this concept by studying how captive grey parrots interact with such musical devices and produce their own kind of "parrot music" in order to learn more about the aspects of their musicality. The musical patterns, rhythms and melody structures generated by the parrots using the musical instruments and interfaces are nevertheless not meant to sound aesthetically pleasing to human ears and goes beyond anthropomorphic musical appreciation.

\section{Background-The Metamusic PEEK Project}

In 2016, a research project was started by the authors of this paper in collaboration with the artist group alien productions and the zoologists and animal keepers of ARGE Papageienschutz. The principal goal of this project was to design and develop musical instruments and interfaces for a group of grey parrots held in captivity at an animal shelter near Vienna. This research is based on an ongoing art project named metamusic [2], which was initiated in 2012 by alien productions. The project aims to generate artistic output while improving the quality of life for grey parrots in captivity with musical instruments and interfaces.

In working with the grey parrots, the artist group has been developing mechanical and electronic instruments and sound toys which can be played by the grey parrots themselves. With the help of the grey parrot experts of ARGE Papageienschutz and further supporters, they created several exhibition installations and held concerts with the parrots. In the course of these exhibitions, the artist group has been examining how the grey parrots react to musical stimuli, have explored their interactions with musical instruments and sonic toys and have tried to establish the extent to which such activities point to musicality in these animals. Since the observations and informal findings of the first three years of work on metamusic seemed promising, alien productions wanted to expand and further develop the project. Especially with regard to instrument design and implementation, they had reached a point where they could no longer move forward on their own and were looking for support in this specialized sphere. The Tangible Music Lab of the University of Art and Design Linz, was approached to collaborate on the project. The four-year period of the project was from March 2016 to June 2019, where we had the final public presentation of the project at the parrot shelter in Vösendorf near Vienna.

It cannot be overstated that strict ethical guidelines have been applied for working with the grey parrots throughout the entire research project. These are comprised of the specifications of ACI research [3] and the strict rules of ARGE Papageienschutz (Section 6.1).

\section{Musicality in Grey Parrots}

At the center of this artistic research project was a changing group of grey parrots of the ARGE Papageienschutz parrot shelter near Vienna. Since 1996, the parrot conservation group has been looking after neglected, smuggled, poorly kept or over domesticated birds and has been fighting to improve the living conditions of parrots and to help protect this endangered group of animals. The parrot shelter is currently taking care of about 180 parrots, from little parakeets to the big macaw parrots. Among the fosterlings are also many grey parrots.

In the metamusic PEEK project, unlike most research in this field, no new grey parrots were purchased or bred. The main focus was on the animals' welfare; consequently, the animals we worked 
with were sometimes given away to provide them with a new and better home, this means that around 50 percent of the grey parrots were exchanged during the project phase.

In the search for the origins of musicality, many researchers, starting with Charles Darwin in the "Descent of Man" (1871), where he devoted ten pages to music [4], point out that musicality can be found in the animal kingdom and has biological roots [5]. Such evolutionary concepts refer to biological functions such as sexual selection, which includes attracting partners and defending territories, mother-infant communication or social bonding in groups.

Recent research in the field of cognitive biology has focused on the role of animals listening to music and further as a concept of enrichment for captive animals [6-8]. Since most of the music is selected by humans, this can lead to anthropomorphic biases. Therefore, the music should be attuned to the animals' auditory skills. For example, creating compositions which are based on utterances of the animals has led to good results in studies with cats [9]. Another approach is to give the animals control over their auditory environment, where the animals can use devices to determine if they want to hear sound and which kinds of sounds they want to hear. Such animal-controlled sounds have the advantage of being available on demand and are a source of experience and learning through interaction [10].

Studies have shown that non-human species also have musicality [11-13] and display forms of entrainment to auditory stimuli $[14,15]$. Entrainment in the context of biomusicology refers to the synchronization of animal movements (e.g., head bobbing in parrots) to an external perceived rhythm. Animal species such as grey parrots, cockatoos, elephants, some primates, pigeons and carps have been found to be able to discriminate between different types of music, prefer types of music to silence and can develop an individual taste in music [6,11,16,17].

There are some indicators, such as vocal learning and entrainment, that speak to high auditory skills and musicality in various animal species [12]. Vocal learning is the ability to modify sounds, learn new sounds via imitation and produce vocalizations. Little is known about entrainment in animals as it is uncommon in animals and involves the complex brain ability to synchronize their movements to a musical beat $[15,16]$.

Aniruddh Patel, an expert on music and the brain in both humans and animals, has proposed the idea that the ability to synchronize movements to a steady beat and emerged as a by-product of vocal learning. Thus, animals that are not vocal learners tend to have no predictive and flexible entrainment abilities [4]. In 2009, researchers disproved the claim that entrainment to music is unique to humans. According to two studies, some parrot species such as grey parrots and cockatoos have the ability to align their movements to an externally perceived rhythm and thus have musical skills and a natural feeling for rhythm. Researchers have observed and documented the existence of spontaneous motor entrainment in parrots such as grey parrots and cockatoos $[15,16]$.

One of the few animal species that has demonstrated both vocal learning and spontaneous entrainment are grey parrots. Grey parrots are also well known for learning to repeat musical patterns and have the ability to reproduce and imitate sounds [13].

Therefore, there have been several investigations focusing on the musicality of grey parrots such as Luciana Bottoni's study on "Teaching a musical code to a parrot: Frequency discrimination and the concept of rhythm in a grey parrot" (2006). Bottoni taught an African grey parrot to express basic elements of music such as intonation and rhythm. The frequency analysis and comparison between the parrot's sequences and randomly generated strings confirmed the acquisition of the intonation concept and the amplitude peak of the notes showed the grey parrot's tendency to maintain rhythmic regularity [13].

Franck Péron investigated the existence of personal musical taste in grey parrots in 2012. He placed a touchscreen in an aviary which could be used at any time by two birds. He observed that the parrots were able to use the electronic device and discovered that they had varied musical tastes and showed different individual musical preferences. One grey parrot preferred classical music while the other one 
like rhythmical pop music. Classical music seemed to have a relaxing and calming effect on both of them [18].

In summary, based on the findings described above, it appears appropriate and promising to work with grey parrots in the context of musicality in animals and auditory enrichment for animals in captivity.

\section{A Taxonomy of Related Works}

In our extended review paper, "Animals Make Music: A Look at Non-Human Musical Expression," [19] we have proposed a classification based on the more active or passive agency that animals can play in the interaction process with musical instruments and interfaces. The analysis and classification of these projects provides a source of data that could potentially lead to further contributions in this field and theoretical improvements in an animal-centered design process. We distinguish between: (1) animal as control source; (2) animals as unconscious performers; (3) animals as trained performers; and (4) animals as voluntary performers. In the following section, we present some projects which we have found to be relevant within our research field.

\subsection{Animal Movement as Control Source}

Many of the musical implementations we have found use a video tracking system to observe animals and create sounds based on the movements of these animals. The most common species used in these systems is aquarium fish. Since the mid-2000s, this idea has been explored in different fields and with various fish species. For example, "The Accessible Aquarium," a long-time project of the Georgia Institute of Technology in Atlanta, is based on the field of informal learning environments [20].

Other fish-based projects such as FuXi: A Fish-Driven Instrument for Real-Time Music Performance [21], Submersed Songs [22], Quintetto [23], Musica sull'Acqua [24], Sonification of Fish Movement Using Pitch Mesh Pairs [25], and Ken Rinaldo's Augmented Fish Reality [26] take an artistic approach. Even though all the projects mentioned above use a video tracking system, they differ from each other in the way in which sound is mapped to the fishes' movement and what kind of sound was generated. Although it has been shown that some fish species such as carp can discriminate between different styles of music [27], and gurnard fish also have audio communication skills [28], these particular abilities have not been investigated within the fish-based projects found in this field.

\subsection{Animals as Unconscious Performers}

This section deals with projects that involve animals directly touching or triggering the interfaces, instruments or sensors and also involves species that have a developed hearing capability. A well-known art project is "from here to ear" [29] by Céleste Boursier-Mougenot. Since 1999, he has been developing musical environments and installations for finches in public exhibitions. The installations combine a set of traditional musical instruments-mainly electric guitars and drums-that serve as a resting place for the finches and produce sounds upon contact. The public is invited to enter the installation space and mingle with the finches, whose movements generate a live music piece. Each installation can be considered as a unique piece that is living and ephemeral; it is determined by the given variables of the situation and linked to the circumstances of the given moment [29]. Influenced by the audience, the finches generate a random sound collage that allows for minimal compositional procedures and choreographies defined by spatial arrangements. This project is currently one of the most established installations in the field of animal-human co authorship in sound installation. Since it has been shown that finches have musical abilities [12,14], it would be interesting to provide them with musical instruments that are adapted to the physical and musical skills of the finches.

\subsection{Animals as Trained Performers}

In this section, we look at projects in which animals become active music performers. Elephants are a species that have been given musical instruments to enrich their lives in captivity. An early 
attempt in this regard was made by the Thai Elephant Conversation Centre with its "Thai Elephant Orchestra". With the intention of creating music with humans, they designed and built massive musical instruments adapted to the physical abilities of the elephants. The instruments that were used in the orchestra were mainly percussion instruments that the elephants could play with their trunks. The percussion instruments ranged from slit drums, marimba-like instruments and gongs to thunder sheets, bells and xylophones. Other instruments included single-string instruments, harmonicas and wind instruments.

The designs of the instruments were adapted to the elephant's anatomy and skills. During the course of the project, it was shown that they could make music together with other elephants and humans [30,31]. The combination of good instrument design and the elephants' musical skills makes this project a promising approach. That the project was founded to raise money for the Thai Elephant Conversation Center and thus became a tourist attraction may have had a negative impact on the animals. For instance, the project focused on training elephants to play human-like music for a human audience. It would have been interesting to see what would have happened without any training, by just providing the elephants with musical instruments and seeing what kind of musical output they created without the need to entertain a crowd of visitors.

\subsection{Animals as Voluntary Performers}

In 2014, the zookeepers of the Smithsonian's National Zoo in Washington D.C. provided their zoo animals with some musical instruments [32]. For example, they equipped their otters with a keyboard and the orangutans with xylophones. The zoo's intention was to enhance the well-being of the captive animals, keep them active and enrich their environment. They used traditional instruments designed for humans such as keyboards, xylophones and harmonicas, which obviously was a disadvantage to some animals with different physiologies.

In the context of ACI research, several studies have been devoted to the use of audio technologies to enrich the living environment of animals in captivity. Fiona French is currently investigating the potential of technological enrichment for captive elephants [33]. The design of the interactive toys for elephants also focuses on acoustic enrichment experiences. For example, one design concept was based on a theremin-like instrument that the elephants could play with their trunks [34]. In collaboration with animal welfare experts and elephant keepers, French has developed prototypes for musical interfaces that utilized sensors and switches for triggering sounds. The sounds were adapted to the elephants' preferences, and $60-70 \mathrm{~Hz}$ low frequencies were used to arouse the interest of the participating elephant Valli [34].

A further relevant study in ACI was carried out by Pons et al. with orangutans at Zoos Victoria in Melbourne. A sound-based interactive system was developed for auditory enrichment. Instead of providing orangutans with human music, the system allowed the animals to explore different types of sounds by manipulating tangible objects. The sound preferences of the orangutans were incorporated into the design process, thus constituting an animal-centered approach. The system potentially allows to study which kind of auditory stimuli are engaging for the orangutans and which mappings would be best to mediate the interactions [35].

In our opinion, the studies of French and Pons could be seen as best practices in the context of ACI, and both approaches could be adapted and used for the development of musical instruments and interfaces for other species such as grey parrots as well.

\section{Sonic Experiments with Grey Parrots}

In our report, "Sonic Experiments with Grey Parrots: A Report on Testing the Auditory Skills and Musical Preferences of Grey Parrots in Captivity" [36], we have documented a series of experiments toward the development of acoustically enriched environments through sonic interfaces and musical instruments for grey parrots living in captivity. These investigations intend to lead to a better understanding of how an individual group of grey parrots perceive, respond to and generate sound 
and music through the usage of technological mediators. It determines the interaction preferences of the involved grey parrots that informed the following animal-centered design process described in Section 6.

In the first practical phase of this artistic research, motivated by research showing that grey parrots have high auditory skills and musical talents $[13,15]$, we wanted to find out more about the general auditory skills and individual musical preferences of a group of African grey parrots held at the parrot shelter. We have carried out sonic measurements and sonic experiments in order to better understand how they perceive, respond and generate sound and music. Our overall aim in this phase was to find and define basic design specifications for the planned series of experimental musical interfaces and instruments. They should be adapted to correspond with the physical capabilities and sonic preferences of grey parrots that we identified in the experiments and thus to take a significant step toward the implementation of musical instruments for the auditory enrichment of a group of grey parrots.

\subsection{Sonic Experiments at the Parrot Shelter}

To test the auditory and musical skills of grey parrots in captivity, we carried out measurements and experiments at the ARGE Papageienschutz parrot shelter in Vösendorf near Vienna. Many of the grey parrots of the parrot shelter that we worked with suffered from a variety of behavioral and mental disorders and had become over domesticated. These birds are often rescued or given away, but usually recover quite well after their admission to the parrot sanctuary. A very striking symptom in captive parrots is the feather-damaging behavior (FDB), which is believed to be rare or does not occur in wild parrots. FDB is generally very prevalent among captive parrots and describes the behavior of birds plucking their own feathers with their beak, which results in damage and the loss of their feathers. FDB is regarded as a multifactorial disorder combining factors such as neglect, isolation, boredom, a permanent stress situation, missing or wrong contacts, lack of care, wrong accommodation, too little movement and unfavorable climate or wrong diet [37].

The subjects of the experiments were 15 grey parrots between the ages of 4 and 40 . They were housed in one group in a $5 \times 4 \times 3 \mathrm{~m}$ indoor aviary, with an additional outdoor aviary of approximately the same size. All experiments took place in the indoor aviary. The aviaries were enriched with parrot tools, and the parrots had free access to food and water. For the experiments, the parrots were not separated. They were free to interact with the test devices and were only rewarded and intrinsically motivated though the sonic feedback generated by their actions. These tests were carried out in cooperation with zoologists and respected the ethical principles of ARGE Papageienschutz (Section 6.1). There was no rewarding by food, and when the grey parrots moved away, the test was stopped. In general, it is very noisy in the parrot shelter environment, and many of the animal keepers therefore wear ear protection.

\subsection{Sonic Pre-Tests}

Prior to the testing of the music preferences of the grey parrots described below, measurements were taken of the loudness, and a frequency analysis was conducted on the calls and songs of the grey parrots over a period of two days. It must be noted that the calls and sounds of the parrots from the neighboring aviaries were also clearly audible in the aviary in which the tests were carried out. We cannot exclude that they also influenced our measurements to some extent. To measure the sound pressure level, we used a Laserliner SoundTest-Master sound level meter and for the audio recordings, an R-09 EDIROL digital recorder. To protect the devices from the parrots, we positioned them in a small cage in the aviary. Our measurements in the aviary found a maximum sound volume of $104 \mathrm{~dB}$. That already lies in the harmful range for human hearing. The average communication volume of the grey parrots was between 60-90 dB. The analysis of the frequency range was run on a spectrogram. The frequency ranged from a minimum of $600 \mathrm{~Hz}$ to a maximum of $3800 \mathrm{~Hz}$. Most of the utterances of the grey parrots were in the range between 1200-2400 Hz. The frequency analysis showed that the basic frequency in the grey parrots' communication was substantially higher than in humans. 
This raises the question of whether we have to pitch up the sounds and music we are working with to make them better perceptible for the grey parrots.

Such frequency examinations on grey parrots in captivity have already been carried out in previous studies by Bottoni [13] and have showed similar results. Due to the particular set of living conditions in the animal shelter and the individual backgrounds of the parrots, we found it interesting to see if there were significant deviations from these previous studies.

Thus, to learn more about the basic hearing parameters of the grey parrots, we also tested their hearing abilities by exposing them to sound. The stimuli consisted of sine waves of different frequencies at an intensity of $70 \mathrm{~dB}$ at a distance of $1 \mathrm{~m}$. The frequencies ranged from below the hearing threshold to levels well above the hearing threshold and with frequencies covering the whole audible range of grey parrots.

For these tests, we used a speaker that was built into our rope swing test station described below. The small loudspeaker was $7.6 \times 6.2 \times 5.5 \mathrm{~cm}$ and had a frequency range from $150 \mathrm{~Hz}$ to $20,000 \mathrm{~Hz}$. The animals were observed to see how they reacted to the different frequencies. A particularly interesting indicator was the head and body shaking of the grey parrots. This behavior was clearly observed at certain frequencies. According to the experts and animal keepers, this behavior can be interpreted as irritation. However, that does not mean that this irritation is felt as negative. Another clear indicator were the utterances and calls of the grey parrots.

Our observations and the evaluation of the animal keepers suggest that the lower limit of sound perception is around $150 \mathrm{~Hz}$ and the upper limit of sound perception is around $7000 \mathrm{~Hz}$. Particularly strong acoustic feedback was observed at $5000 \mathrm{~Hz}$. Results that do not differ significantly from previous studies [13,38].

\subsection{Experiments with the Rope Swing Test Station}

The rope swing test station is based on a typical tool for parrot enrichment-a rope swing with an outer diameter of $29 \mathrm{~cm}$. Rope swings are used for physical enrichment by providing swinging and climbing opportunities and thus they often serve as a resting place for the parrots. A rope swing had already been used as the swing instrument by alien productions as part of the initial metamusic project. An accelerometer sensor was attached to the rope swing to trigger sound with simple rhythms and melodies when parrots interacted with the ring. Since the swing instrument was well received by the parrots, we decided to further develop this instrument to test the auditory and music preferences of the participating grey parrots. First, we integrated the accelerometer sensor at the bottom of the rope swing where the parrots prefer to sit. Thus, we experimented with radio-frequency identification (RFID) antennas that were also integrated at the same place. The adapted rope swing was attached to a small case which housed a Raspberry Pi mini-computer and electronics for the sensors. This setup made it possible to trigger different sounds, record all the interactions and opened up the opportunity to identify the individual parrot interacting with the rope swing. For the purposes of our tests, we made a second copy of the rope swing. Both rope swings were mounted side by side in the aviary. The distance between the rope swings was chosen in such a way that the parrots could easily change from one swing to the other. We had three long-time test phases over a period of three months. We carried out different sonic experiments within these test phases of three to four days. The rope swing test station was accessible $24 \mathrm{~h}$ a day, and the interactions were digitally logged. Most of the time no persons were present during these test phases.

Basically, there were two setups:

1. One rope swing was active, which means that the swing responded with auditory feedback when a parrot interacted with it. The other rope swing did not give auditory feedback. In this way, we tried to find out which rope swing the grey parrots preferred-the rope swing with sound, or the rope swing without sound.

2. Both rope swings were active, which means that both swings responded with auditory feedback when a parrot interacted with them. The rope swings gave different auditory feedback. 
For example, one swing played a simple melody while the other swing played the same melody with a changed pitch, or one swing played a song with human vocals while the other swing played the same song without vocals. In this way, we tried to find out the music and auditory preferences of the individual grey parrots.

The following sounds were used for testing: single notes from different instruments, simple melodies at different pitches, songs with and without human voices or beats at different speeds. The volume intensity for testing was about $70 \mathrm{~dB}$ when a grey parrot sat on the swing and triggered the sound. The average volume of communication of our grey parrot participants is $70 \mathrm{~dB}$. In general, grey parrots are very territorial animals and thus the birds were not always free to move within the aviary. It was therefore important to find a suitable place to hang the test station in the aviary so as many birds as possible could interact with it. Furthermore, the accessibility of each rope swing played an important role. It made a difference in the frequency of use if the swing was reachable by using a branch or if the parrots had to fly to the swing. In addition, there were the individual preferences of the grey parrots themselves-some liked to use rope swings, others not. Since digital logging also led to errors, this data is not very significant. For example, errors occurred when the birds passed and bumped the rope swings, or when they played around with the test station housing with their beaks.

However, some general knowledge can be derived from this data. Most interactions with the rope swing test station were digitally logged in the early morning hours between five and nine o'clock. Both swings-with sound and without sound-were regularly used and triggered. Based on what we observed, the animals actively triggered the sound of the active swing and used this swing over a longer period of time- from 5 to $30 \mathrm{~min}$. In the second test setup, when both rope swings were active, we observed that music with a continuous beat was favored to single notes. In response to music with a continuous beat, it often happened that the grey parrots spontaneously entrained by bobbing their heads and responded with utterances. We could not prove whether grey parrots tend to prefer music with human voices to music without human voices or which pitch they prefer. Wittgenstein, a very active 4-year-old female grey parrot, was observed to repeatedly trigger the sounds at the rope swing test station. The distinctive jerky movements of Wittgenstein suggest that she was triggering the sound on purpose. The individuals from our group of grey parrots generally preferred a loudness and pitch matching their own communication habits.

\subsection{Experiments with the Joystick Test Device}

The predecessor of the joystick test device was the joystick instrument by alien productions. The joystick test device is battery-powered and consists of a $25 \times 17 \times 10 \mathrm{~cm}$ grey box, with two wooden joysticks, a perch for one bird and the electronics installed inside the box. The two wooden joysticks were originally popular tangible toys for grey parrot enrichment. These are mainly operated by the parrot's beak and leg. The wooden joysticks had different colors (yellow/green and orange/blue) and were mounted next to each other $10 \mathrm{~cm}$ apart. The interaction design for our experiment was as follows: One grey parrot sat on the perch which was mounted so the bird could interact with the two wooden joysticks. The parrot could choose freely between the two joysticks, which could be easily moved by the parrot's beak. By moving the joystick, the parrots could generate different sounds. If there was an auditory response, it came directly from the small speaker placed inside the grey box.

The test setups for this experiment were similar to the ones for the rope swing test station:

1. One joystick was active, which means that the joystick triggered sounds when a parrot moved it. The other joystick did not give auditory feedback when moved. In this way, we tried to find out if the parrots prefer the joystick with silence or the joystick with sonic feedback.

2. Both joysticks were active, which means that both joysticks responded with auditory feedback when a parrot interacted with it. By using different sounds, we wanted to gain a better understanding of the music and auditory preferences of the individual grey parrots. 
We used experiments to compare, for example, if the individual parrot preferred a drum beat to a single note or a slow drum beat (90 BPM (beats per minute)) to a faster one (120 BPM). The volume intensity for testing was between 60 and $80 \mathrm{~dB}$ for the grey parrots when they were sitting on the perch and triggered the sound. The joystick device test was carried out in the presence of a person that motivated the parrot to interact with the joystick device. A test phase lasted between 20 and 30 min depending on the motivation of the birds. Since the joystick device is battery-powered and wireless, it was possible to move around freely in the aviary and offer the device to different grey parrots. In general, the joystick test device was well received. Some of the grey parrots were willing to spontaneously interact with it. As with the rope swing test station, we observed that the parrots preferred music with a continuous beat to single notes. In the experiments with faster and slower musical beats (BPM), the grey parrots did not show any clear preferences. Another basic insight was that the musical taste of grey parrots is apparently very individual as in humans. Coco, a 40-year-old female grey parrot, showed clear preferences for the joystick test device. If the device was positioned on the ground, it was occupied and used for more than $60 \mathrm{~min}$ by her. She used the joysticks to trigger sounds and quickly found out which joystick triggered the sounds and which not. In response to the sonic feedback from the device, she started bobbing her head and making utterances.

The sonic experiments with grey parrots show informal results that suggest that the design and use of musical instruments and interfaces can possibly help to improve their quality of life in captivity. The grey parrots intrinsically participated in the experiments, interacted with the provided test devices and gave positive feedback by bobbing their heads or making utterances. Thus, our efforts are a significant step toward the acoustic enrichment of grey parrots in captivity. By logging the experiments digitally, recording videos and observing the grey parrots' behavior, we were attempting to determine what kind of sonic and interactive experiences the individual parrots prefer in their interaction with the proposed test environments. In the following project phase, we focused on the design of a series of experimental musical interfaces and instruments that are adapted to these physical capabilities and sonic preferences of our group of grey parrots.

\section{The Design}

This section describes the process and the methodology used to design musical instruments and interfaces aimed at providing auditory enrichment for grey parrots living in captivity. Based on the cognitive, physiological and auditory abilities of grey parrots, and their intrinsic interest in acoustic and physical interactions, we have developed and tested various interactive instrument prototypes from an animal-centered design perspective [39]. In the previous section, we analyzed the physical and musical skills of a group of grey parrots, and here we present the design results for auditory enrichment in the context of ACI and artistic research. This investigation should lead to a better understanding of how grey parrots interact with technological mediators, respond to sound devices and create "parrot music," with potential benefits for their well-being while living in captivity.

\subsection{Methodology}

The design of interactive technologies for grey parrots in the field of artistic research and musical interaction design is new and therefore requires careful consideration regarding an appropriate and responsive framework for the process of developing such environments. Our process for designing musical instruments is mainly based on the findings of ACI and biomusicology, as well as our own observations and an analysis of the physical and acoustic capabilities of the various participating grey parrots. One of the main goals of this artistic research project was to develop an approach that allows grey parrots to voluntarily participate as actively as possible in the design process without the application of any clicker training or food-based reward training. The voluntary participation of the grey parrots in the different experiments is ensured by allowing the grey parrots to freely decide whether they wish to participate in the research activity and by creating experimental setups that assure the exercise of free will by allowing the grey parrots to move away from the experiments at any 
time. We take the fact that the grey parrots actively move towards the instrument, generate sounds with it and respond to the sounds as a sign of their voluntary participation.

When working with the grey parrots at the ARGE Papageienschutz aviary, we complied with their ethical requirements:

- No spatial separation (of individual grey parrots)

- No training (especially no typical parrot training with clicker or target stick)

- No rewarding with treats

- Voluntary participation

\subsubsection{Participatory Design}

To actively inform the design process within the various stages of our prototypes, we have preferred to use the playful interaction between grey parrots and humans as a co-design method for the development of musical instruments for this animal species. The joint musical play, or as we call it, the "Jam Sessions", have yielded several insights into the individual preferences of each grey parrot and their general forms of interacting with natural, artificial or technical artifacts. The unstructured activities within the "Jam Session" support the embodied dialogue to exchange meanings and discuss outcomes. In the context of ACI even structured activities and formal training of animal participants can be regarded as participatory [40]. We strongly believe that our free participatory design approach leads to more creative outcomes, more usability of the musical instruments and fulfills all ethical research principles. The reactions and observed preferences of the grey parrots when interacting with the proposed devices has continuously informed the iterative design process.

The "Jam Sessions" have opened a wide range of possibilities to gain more knowledge about our group of grey parrots at the parrot shelter. These are the different aspects that have been implemented during the artistic research and participatory design practice for and with grey parrots:

- $\quad$ Artistic musical practice (jamming)

- Preference tests (forms of interaction, materials, sounds)

- Evaluation (grey parrot user tests, observations)

- Foster bonding (between animals and humans through musical instruments)

The duration of the "Jam Session" was usually between 10 and 60 min and was immediately interrupted whenever the grey parrots moved away or showed negative signs. The very playful approach of the "Jam Sessions" was an appropriate method for overcoming the limits of grey parrot-human communication by making music and sound together. Intrinsic motivation also plays an important role in this context. The motivation to engage with the musical instruments should arise from the grey parrots themselves. The cognitive challenge of interacting with musical instruments and the musical response should themselves be a reward and enrichment for the grey parrots. Making music is the spontaneous and voluntary activity undertaken for the parrots' personal enjoyment. The reward is the inherent playful activity and its sonic response, and not just an action to get treats. In short, playing with music replaces the peanut as a reward system and therefore should encourage the animal to continuously interact and play with the musical interface. Beyond the process of observation, measurement and analysis, a more reliable methodology that allows the grey parrots to participate in an animal-centered design process (Figure 1) itself has yet to be found.

The design should avoid any conditioning of the animals but instead support their inherent acoustic capabilities and needs. Instead of providing grey parrots with what we believe is pleasant to their ears, the musical interface approach gives them control over the sonic stimuli. In this approach, the grey parrots can explore different types of interactions with the devices and sounds by playfully interacting with the musical interfaces. 


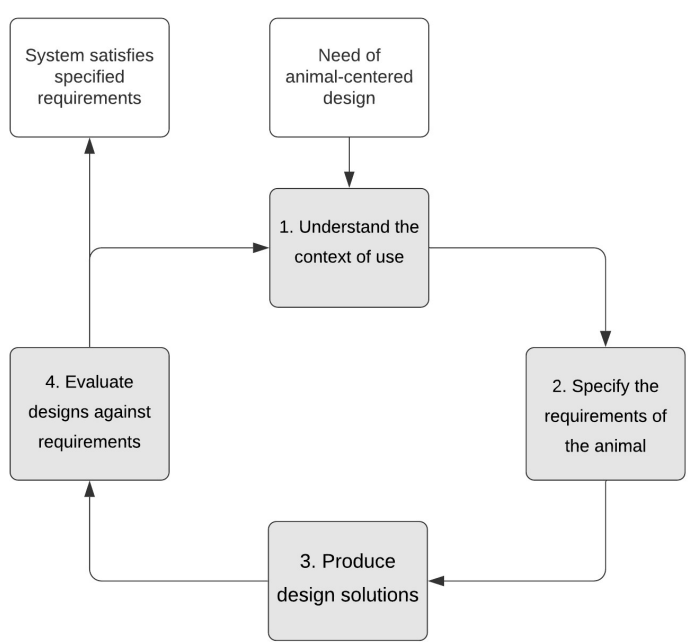

Figure 1. The applied animal-centered design process.

\subsubsection{Interaction Design}

Animal interaction not only always includes an animal and a certain technology, but often a human participant, researcher and/or animal keeper [41]. In our case, this means the interaction between animal and instrument often also includes keepers, artists and researchers. Interaction refers to the way in which parrots handle and respond to the musical instruments and interfaces and is obviously primarily determined by the physical and cognitive abilities of each species. What happens exactly within the animal while interacting is generally unknown, but we, in collaboration with the animal keepers, tried to interpret the behavior of the grey parrots. Therefore, the animal keepers participated in the process through their zoological knowledge and experience with the parrots. We observed the parrots' behavior when playing, exploring and interacting with the musical instruments and other artifacts within their environment. A good understanding of the parrots' body language and posture is essential for determining positive and negative responses to the design of the instruments. Grey parrots primarily interact with instruments by means of their beak, but sometimes a leg is also involved as a support, for example, to hold a device. In general, the parrots like to chew, pull and peck on most artifacts and interfaces, with a visible desire to disassemble or destroy them. In order to encourage this behavior, we have had good results from providing them with a wooden branch equipped with a piezo pickup. This setup has evolved and is presented below as the branch instrument. Branches are generally used as an enrichment toy for the aviaries, and the parrots like to nibble and chew on them and peel off the bark. We have encouraged this natural behavior of the grey parrots and added a sonic stimulus to it by amplifying the sound that occurred during these interactions. This has allowed us to find a good starting point through the use of familiar materials in combination with encouraging natural behaviors such as pecking or chewing.

\subsubsection{Physical Design, Materiality and Color}

As mentioned above, a good strategy is to use materials which the grey parrots are familiar with In the context of this project, this generally refers to the existing equipment and enrichment of the aviary. Commonly used materials are, for example, wood for perches, metal grids, ropes, cardboard, plastic toys and fresh branches.

We observed a general curiosity toward artifacts that we added to the environment, leading to an overall exploration and a tendency toward trying to disassemble the whole artifact. During our initial experiments, we tried to protect the technical instruments from being damaged by the parrots by explicitly trying to build them very sturdy. However, it quickly became clear that the instrument prototypes were far more interesting for the parrots if they at least partially appealed to their exploratory and destructive drive, as we observed with our piezo-equipped wooden branch. 
In the case of the tube instrument described below, we initially used a cardboard tube, which was well-received by the parrots. As the cardboard tube quickly suffered damage, we tried replacing the cardboard tube with a natural and sturdier bamboo tube. Surprisingly, the parrots then completely ignored the instrument and were reluctant to play with it. According to the animal keepers, the grey parrots are not familiar with bamboo, and the material is therefore suspicious to them. Therefore, we had to take a step back and tested different materials for the tube instrument. We finally decided to use transparent acrylic glass as the material for the tube. This material has been well-accepted by the parrots. It is familiar to them, as many enrichment toys use this acrylic material. In general, the neutral appearance and the strength of plastic tubes makes them a good material for the instrument cases and also adds a functional aesthetic that matches our needs. The neutral monochrome colors (white, grey, transparent) of the tubes make sense to us because we do not want the parrots to be distracted by the color of the instruments and thus not engage with the generated sounds. For example, the grey parrot Wittgenstein is very interested in red objects and can be easily motivated to interact with instruments by using red attractors. We assume that such color-motivated interactions have little relevance for our research on auditory enrichment for grey parrots. We have therefore strived for a neutral color design. The use of colored wood cubes from parrot toys has helped somewhat in initially drawing the parrots' attention to the instrument and its usability. We have subsequently observed that the grey parrots react differently to the colors and materials of the instruments. Other attributes such as the smell and the taste of the material might play an important role here, but we have not been able to investigate this in further detail. Generally, we were making sure that no sharp edges or toxic materials were used.

\section{Instrument Implementations}

In order to develop the musical instruments, we regularly visited our group of grey parrots at the shelter over a period of two years. As with the previous experiments, all activities took place in the indoor aviary. The grey parrots were free to interact with the musical instruments and were rewarded and intrinsically motivated though the sonic feedback generated by their actions and we also took into account the presence and influence of us as the experimenter. The designs of the instruments have been informed by our research of the literature, our earlier sonic interaction experiments with grey parrots and the anecdotal experience and observations from the initial metamusic project by alien productions. An instrument from this initial project period that has worked particularly well is the gong instrument.

\subsection{Gong Instrument}

The gong instrument (Figure 2) had been developed by alien productions for a previous exhibition as part of the initial metamusic project. The instrument consists of a floating metal plate, which is mounted with metal springs on top of a case. The plate is equipped with a piezo pickup for sensing the impact interactions, and the case houses and protects the necessary electronic equipment. The gong is a percussive instrument in which the grey parrots generate sound by pecking with their beak onto the metal plate. In the exhibition installation, these pecking sounds were amplified, manipulated with sound effects such as reverb effect and played back to the parrot aviary via a general PA system. Since pecking is a natural territorial behavior in parrots, the instrument was very well-received and used regularly. However, the smooth surface of the instrument made it difficult for the parrots to walk and rest on the instrument. For this reason, blue sandpaper was applied to the surface of the case of the instrument. It remains unclear how the sounds which were played back to the aviary affected the other grey parrots. During our observations, we were unable to detect any stress behavior such as other birds in the aviary fleeing, but we generally suggest that the sound should preferably come directly from a speaker inside the instrument to not affect other parrots in the aviary. 


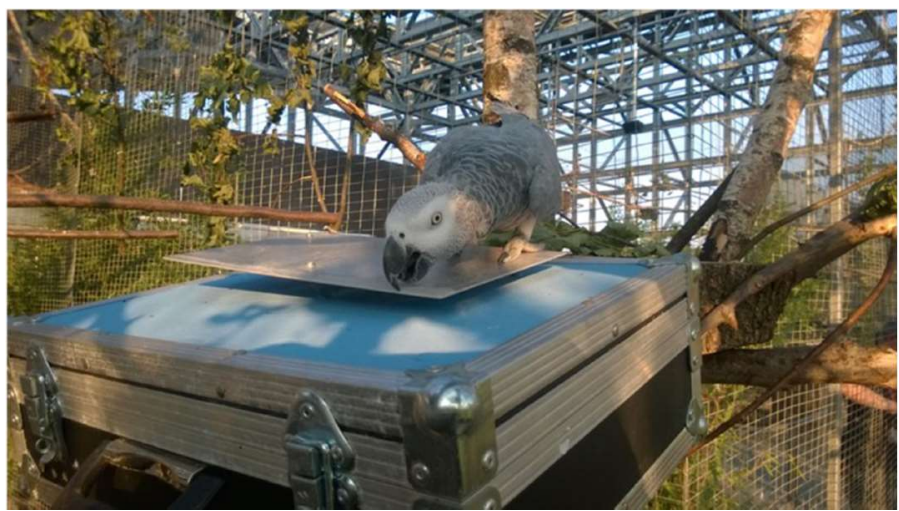

Figure 2. Billy playing the gong instrument; (C) alien productions.

\subsection{Chime Instrument}

This simple and purely acoustic percussive instrument (Figure 3) is based on a wind chime with the audible musical notes G-A-B-D-A-G-B-D. The eight tones are produced by eight metal rods within a cylinder which are struck by a disk attached to a cord with a wind sail.

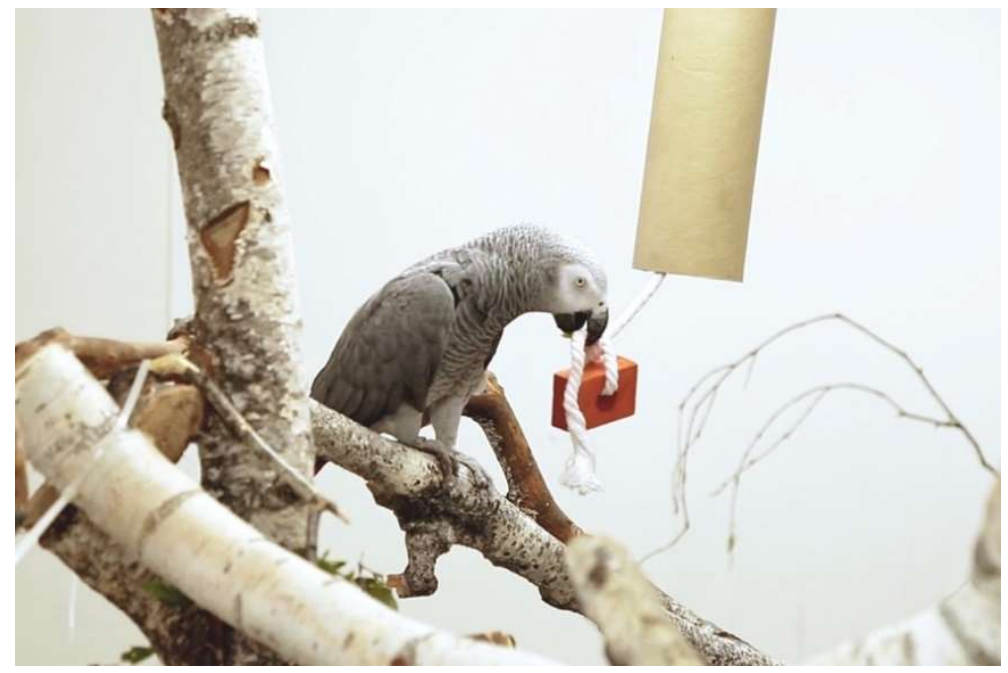

Figure 3. Rosi playing the chime instrument. Screenshot from video by Elisa Unger.

The sound of the wind chime was positively received by individual parrots such as Wittgenstein and Rosi during the "Jam Sessions" and was therefore adapted as an auditory enrichment instrument for the grey parrots. The cord to operate the instrument was renewed and instead of the wind sail, a colorful piece of wood from a parrot toy was attached to the cord. A cardboard tube was used as an additional protective resonator. This modification was also designed to motivate the parrots to interact with the instrument's case. Cardboard in various shapes is often used for enrichment in the parrot shelter, and we assumed that the use of this material would make the instrument more familiar to the parrots and motivate them to chew on and tear at the instrument. We observed various parrots interacting with the chime instrument.

The parrots interacted with the chime instrument by pulling on the rope with their beak or a leg; nibbling and destroying the piece of wood attached to the rope; or, less frequently, nibbling on the cardboard resonator. Mostly, they interacted with the attached piece of wood, and it is therefore questionable to what extent the responsive sound of the instrument was the motivation for the interactions. The color of the attached piece of wood also had an impact on the frequency of the interactions. For example, with a red piece of wood, we observed more interactions than with other 
colors. Through these interactions, a sound carpet was created, which could subsequently be picked up by a microphone.

\subsection{Branch Instrument}

The branch instrument (Figure 4) is an electroacoustic instrument that makes the grey parrots' interactions with the branch and the additionally attached ludic elements audible. As described above, branches are always used for enrichment in the parrot shelter aviary. The parrots sit and move on the branches, peel off the bark and rub their beaks or knock on the wood. We chose a branch from a regional elderberry shrub because we thought its particularly soft wood and soft bark would stimulate the interest of the grey parrots in destroying the branch. By building piezo microphones into the branch, the instrument made the grey parrots' interactions with the branch audible. Additionally, to encourage playful interactions with the instrument, a metal spring was mounted, which could be used to make additional sounds with the two wooden cubes mounted on a cord next to the spring.

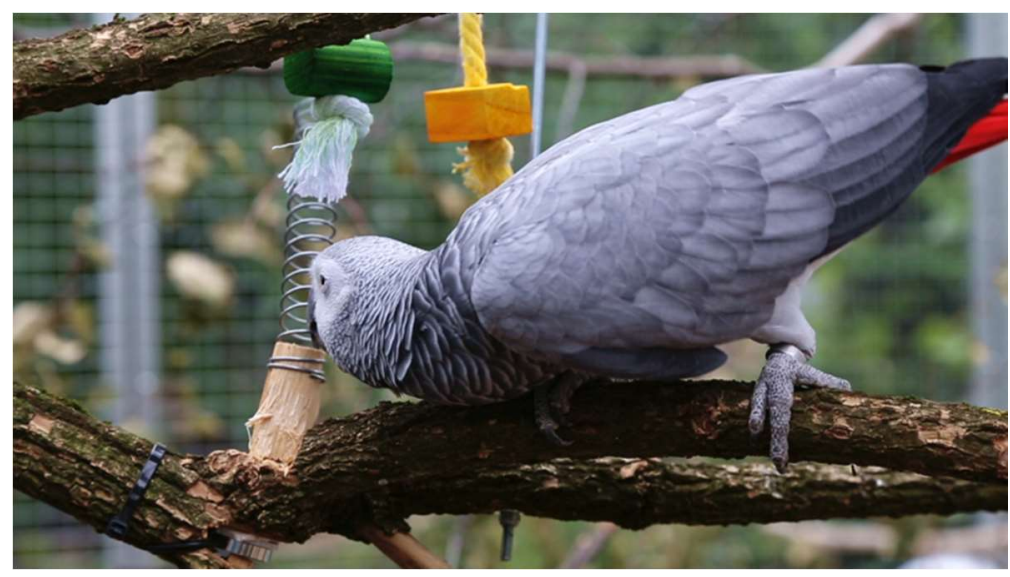

Figure 4. Nepomuk and detail of the branch instrument. Screenshot from video by Elisa Unger.

We observed that the grey parrots moved naturally on the branch while their movements were amplified. The additional spring toys aroused the interest of the parrots, and they played with them. We could not observe a change in the grey parrots' behavior due to the sounds generated by their actions.

\subsection{DJ Instrument}

The disc jockey (DJ) instrument (Figure 5) is based on a $15 \mathrm{~cm}$ diameter foraging wheel, which was originally designed for the playful enrichment of the feeding process. Foraging wheels are not only used for feeding but are also employed as physical and cognitive enrichment toys by providing challenges in which the parrots have to spin a wheel to collect their treats. When a grey parrot spins the wheel of the DJ instrument, the parrot will not be rewarded with food but with sound. The parrots usually use their beak to spin the wheel. The appearance of the instrument and the way in which the parrots interacted with the device strongly reminded us of a DJ scratching vinyl records on a turntable and therefore we adapted the sound design of the instrument to this analogy.

The feeding wheel is attached to a bent right-angled plastic pipe and equipped with a rotary sensor that triggers sounds when the parrots turn the wheel. In addition, visual feedback is provided by a LED attached to the wheel. In keeping with the turntable theme, we also designed a corresponding scratching sound as a sonic reward for the parrots. Since the scratching sound was well-received by the parrots, we have decided to further develop this instrument into a parrot turntable. The adapted right-angled pipe houses a Raspberry Pi computer, an Arduino board and an amplified speaker for direct sonic feedback. This setup makes it possible to directly trigger scratching sounds when the wheel is turned. It is possible to upload different audio files to the instrument. When the parrots turn 
the wheel, it scratches through the loaded audio file. Depending on the speed and duration of the rotation, different scratching sounds, similar to DJs' vinyl scratching, are generated. The instrument is battery-powered and can be easily installed at different locations and therefore in the different territories of the individual grey parrots in the aviary. In general, grey parrots are very territorial animals, and therefore individual birds were not always free to move within the aviary. The mobility of the instrument compensates for this behavioral limitation.

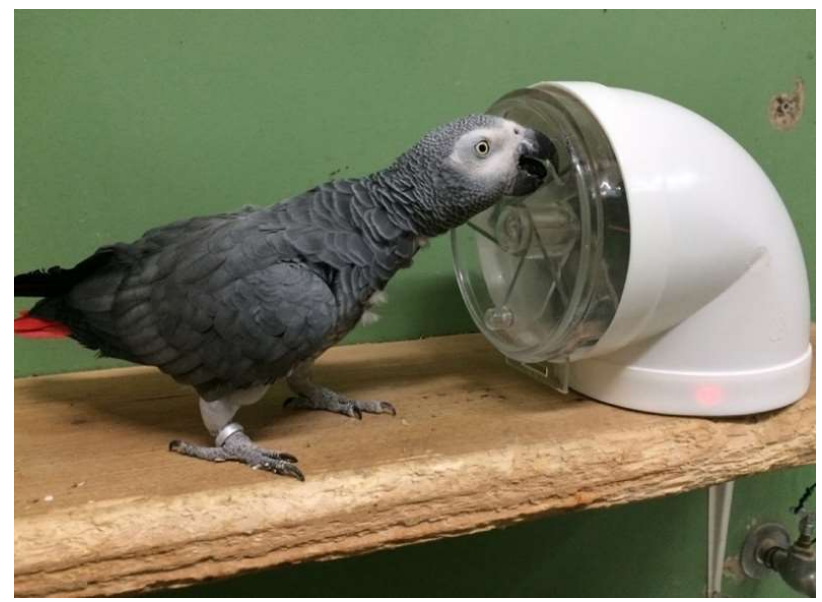

Figure 5. DJ instrument played by grey parrot Pauli.

Since the parrots were already familiar with this form of spinning interaction, they were able to quickly learn how to operate the instrument in order to receive their sonic treat. In further experiments with the DJ turntable instrument, we wanted to find out in more detail whether different sounds are perceived as a reward or a positive experience by the grey parrots.

Some parrots immediately engaged with the DJ instrument. The grey parrots Pauli, Nepomuk and Cocomiso showed clear interest in interacting with this instrument and used it for a period of several minutes. The parrots intuitively found out how to trigger the scratching sounds and in response, started bobbing their heads and responded with utterances. This kind of behavior can be interpreted as positive feedback and indicates excitement and interest.

\subsection{Tube Instrument}

The tube instrument (Figure 6) has been designed as a collaborative instrument in which a parrot can play "hand-in-hand" with another parrot or a human collaborator. Grey parrots mostly live in monogamous relationships and prefer to engage in activities with their partners. The tube instrument therefore intends to stimulate the birds' interest in interacting and discovering things together or interacting with other humans who are part of their flock.

The instrument consists of a tube with a spring reverb installed inside that can be triggered from both sides by pulling on ropes that reach out from each end. The instrument is battery-powered and consequently also mobile and generates reverberating sounds. The sonic response comes directly from a small amplified speaker placed inside the tube. The grey parrots interacted with the instrument exclusively by pulling on the rope with their beaks, thus creating a metaphorical tug-of-war. As already described above, we initially used a cardboard tube, which was later replaced by a bamboo tube. After switching from cardboard to bamboo, the parrots did not want to interact with the instrument, so we had to carry out material tests and opted for acrylic glass for the final version of the tube instrument. In the context of a musical performance, this instrument could also be used as an effect device by additionally modulating external sound sources by interacting with the instrument.

Regarding the collaborative design, the tug-of-war approach turned out to be appropriately chosen since two parrots could interact simultaneously with the instrument. They enjoyed the competitive 
and destructive experience and also responded to the sonic reverberations generated by their activity. We observed that the grey parrot Bimboli fluffed his feathers when interacting with the instrument, a behavior that animal experts interpret as a sign of positive excitement.

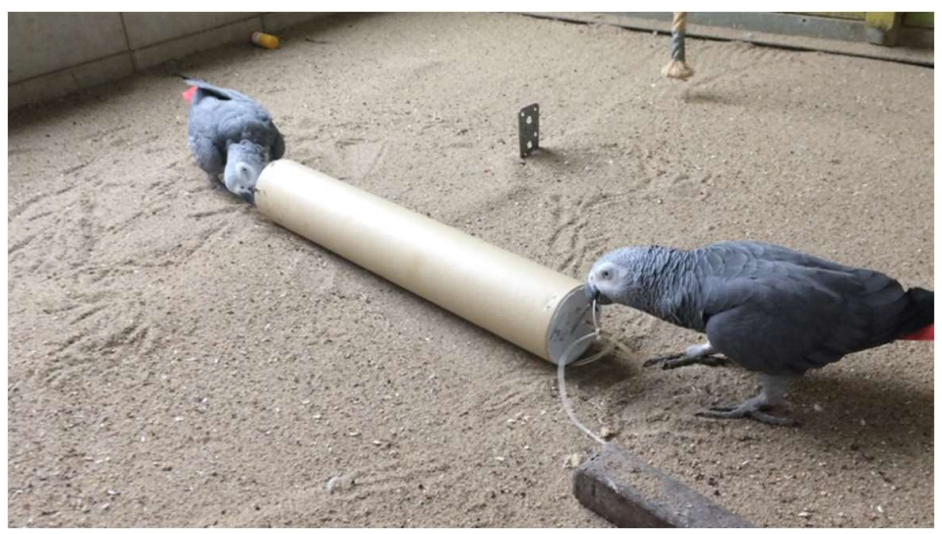

Figure 6. Tube instrument showing a collaborative interaction.

\subsection{Vox Instrument}

Grey parrots show the exceptional ability to mimic human speech and environmental sounds $[13,42,43]$ and therefore we also focused on designing an instrument that specifically encourages this behavior. We developed a vocal feedback instrument into which the parrots should shout, speak or sing. The idea was to record the sounds of the parrots and then play back an auto-tuned feedback with delay and reverb effects of their utterances. Such a practice could hypothetically even lead to the self-training of pitched notes for grey parrots.

The vox instrument (Figure 7) consists of a plastic pipe system with three openings. A children's microphone is mounted to the larger open end and receives the sounds of the parrots. At the other two smaller open ends, small speakers are installed for a direct sonic feedback. The necessary electronics such as a Raspberry Pi, soundcard and amplifier board were also built into the pipe system. Once the microphone registers sound from the grey parrots, these sounds are slightly delayed and transformed by the instrument. The intended result is a call-and-response interaction between the grey parrot and the instrument that involves different sonic elements, such as reverb, echo and pitch shift.

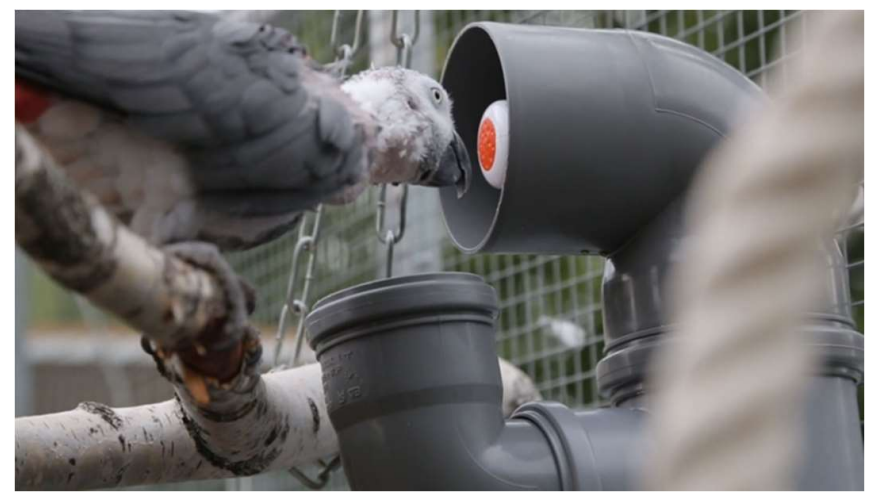

Figure 7. Cocomiso interacting with the vox instrument. Screenshot from video by Elisa Unger.

The grey parrots interacted with the vox instrument by nibbling and chewing on the microphone and the pipe with their beaks and showed responses to the instrument's sonic feedback. A direct speaking or singing into the microphone or call-and-response interaction with vocalizations has not been observed so far. 


\subsection{Reel Instrument}

Another design idea involving the construction of a drum sequencer instrument is based on the outstanding rhythmic entrainment capabilities of grey parrots. The reel instrument is intended to be used by the parrots to generate rhythmic patterns. We have observed that some parrots bob their heads to continuous beats of music. Thus, this drum machine instrument could encourage and promote this behavior. The first experimental approach towards such an instrument utilized bending rulers, which allowed the parrots to modify different beats and rhythmic patterns by bending flexible rulers. Tests with this bending ruler prototype (Figure 8) were not satisfactory. Although the parrots were interested in interacting with the rulers, they had difficulty bending the rulers with the integrated sensors to trigger the sound. Therefore, we had to rethink the interaction concept.

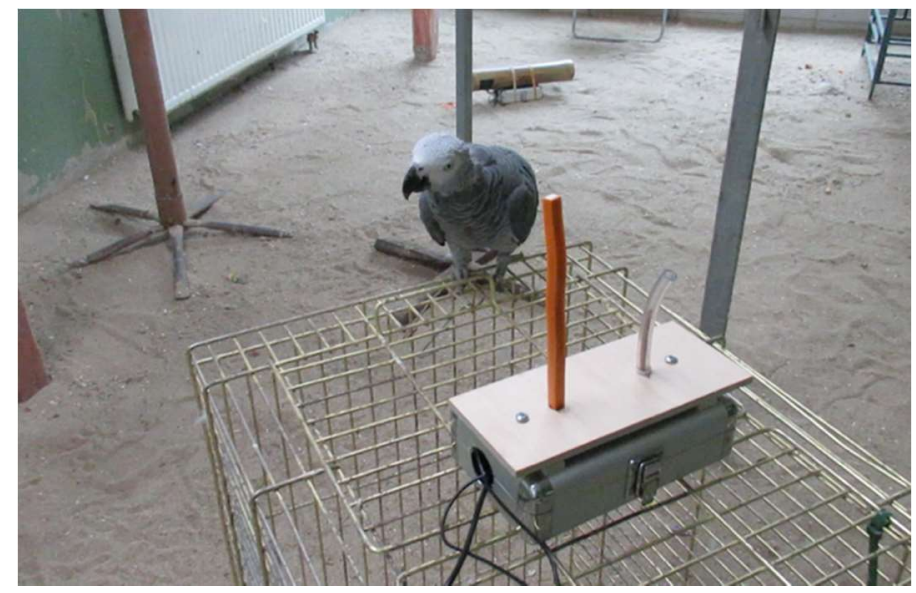

Figure 8. Prototype for a drum sequencer instrument with bending ruler.

The following concept of the reel instrument (Figure 9) is like the DJ instrument in that it is based on an enrichment toy for creating a challenging and playful process for the parrots. With this toy for physical and cognitive enrichment, the parrots must turn four wheels with their beaks to collect their treats. We equipped the four wheels with magnets that could individually activate reed switches to trigger different sounds. As previous experiments have shown, percussive sounds are well-received by the grey parrots and therefore we used drum sounds for this instrument. Each of the four wheels has been assigned a specific drum sound. By turning the wheels, the individual sounds are triggered, and turning different wheels allows the parrots to generate rhythmic drum sequences. The instrument includes a Raspberry Pi computer, an Arduino board, an amplifier and a speaker for direct sound feedback. Grey parrot Wittgenstein and others showed interest in interacting with the device and used it. The grey parrots triggered different drums sounds and responded with bobbing their heads and utterances.

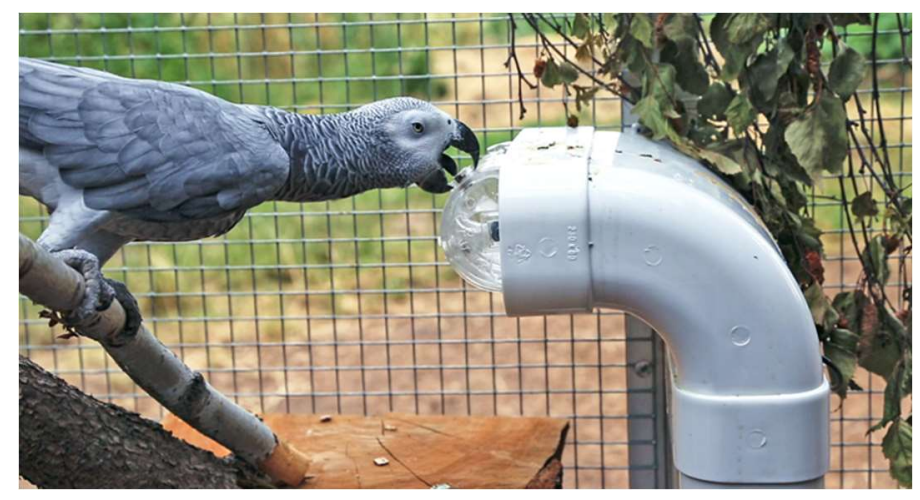

Figure 9. Wittgenstein on reel instrument. Screenshot from video by Elisa Unger. 


\section{Research Results}

In the animal-centered design process, we were always careful to consider whether the musical interfaces we had developed actually have potential benefits for the grey parrots. There are indications that the parrots have individual preferences in terms of interaction styles and sonic feedback. Since we have always worked with a group of grey parrots, we do not know what the side effects of the musical output of a single parrot, for example, when pecking on the gong instrument, might be on the rest of the group. In captivity, the parrots need environmental enrichment and cognitive challenges. Toys and foraging exercises are intended to reduce the chance of behavioral problems. Confronting the grey parrots with cognitive challenges when interacting with musical instruments could provide additional enrichment for them and help reduce behavioral problems such as feather picking, fearfulness and aggression. Grey parrots are flock members and like to be where the action is. Thus, our approach towards developing collaborative instruments also appears adequate. In addition, the musical instruments and interfaces provide the animals with individual control over their shared sonic environment. The sonic interaction between animals, instruments and humans can help foster social relationships, compensate for a lack of social interaction and eventually improve the quality of life of grey parrots living in captivity through the musical activities.

The results and observations of this artistic research project can be regarded as basic research and subsequently could be of use for researchers in areas such as ACI or HCI and might also be interesting as an experimental approach in biomusicology.

\subsection{Interactions}

The grey parrots primarily interact with the instruments via their beaks. This was not clear at the beginning of this artistic research project, and there were also some considerations to build instruments for leg interactions only. These design concepts were subsequently not pursued and implemented. In some cases, there is still leg interaction involved, for example, to hold a part of the device, or if the musical instrument allows the parrot to climb or rest on the instrument such as the gong instrument or the rope swing test station. In the special case of the rope swing test station, we can speak of full body interaction. In general, the parrots like to chew, pull and pick on the instruments and interfaces, with a strong impulse to dismantle or destroy them. To promote these behaviors, the instruments have been adapted for beak interaction and suitable materials have been selected.

\subsection{Objects}

It turned out that the use of objects the grey parrots were already familiar with led to faster adoption of the instrument. Consequently, for many of the instruments, the design concept included enrichment toys and materials that the grey parrots were used to as a source material. In contrast to the ready-made instruments of the initial metamusic project that the parrots were not familiar with, we used objects and toys they knew to develop novel instruments. Both durable as well as easily destructible instruments were built. The easily destructible instruments or destructible parts of the instruments were of particular interest to the grey parrots and stimulated interactions with them such as nibbling, peeling, pecking, knocking and ultimately eating.

\subsection{Materials}

Commonly used materials for the instruments were wood for perches, metal grids, ropes, cardboard, plastic toys and fresh branches. For the DJ instrument and reel instrument, we used different enrichment toys like feeding wheels that the parrots already knew how to use. What was more challenging and disadvantageous was the use of new materials that the grey parrots were not familiar with. In Section 6.1.3, we described, for example, the case of how the tube instrument was not used anymore because unknown materials were used in the construction of the new version. We first used a cardboard tube for the prototype of the tube instrument, which was especially well received 
by some of the grey parrots. Since the cardboard tube was quickly damaged by the interaction with the parrots' beaks, we replaced the cardboard tube with a natural and more durable bamboo tube. Surprisingly, the parrots then completely ignored the instrument and hesitated to play with it. It turned out that our group of grey parrots were not familiar with bamboo. Therefore, we had to take a step back and test different materials for the tube instrument.

\subsection{Sounds}

The sound design of the instruments was also of great significance. The tests on the auditory skills and musical preferences of our group of parrots showed that their lower limit of sound perception is around $150 \mathrm{~Hz}$ and the upper limit is around $7000 \mathrm{~Hz}$ and most of the utterances of the grey parrots were in the range between 1200 to $2400 \mathrm{~Hz}$. From this we inferred that it made no sense to work with very high or low audio frequencies which were not in this spectrum. Generally, the grey parrots have no trouble perceiving the human voice and music; moreover, it can sometimes get very loud in the aviary, so the sound has to be played at a certain volume in order to be heard properly.

A frequency analysis showed that the basic frequency of the grey parrots' communication was substantially higher than humans. This led to the sound design question of whether we should pitch up the sounds and the music we were working with, in order to make it easier for the grey parrots to perceive them. We have conducted several experiments with different pitches of melodies but could not observe any differences in perception. The question of adjusting the pitch cannot be answered in the context of this work but would certainly be an interesting research question for future research projects dealing with the auditory abilities of grey parrots or in the field of biomusicology.

We were able to pass on the expertise we had gained from this artistic research by presenting and discussing our research approach with the interdisciplinary organization team and the participating ACI researchers at the "SoundJam" workshop at the ACI conference in 2018 [44].

\subsection{Individual Preferences}

By observing the grey parrots in the aviary, we were able to identify individual preferences in terms of interactions, territorial behaviors or favored objects and materials. Instruments were developed for individual grey parrots on the basis of the intended area of use in the aviary and the parrots' preferred forms of interaction. For example, the rope swing test station was designed for parrots that preferred the upper area and for individual parrots that liked to play with ropes and swings. A few parrots also liked to explore the floor of the aviary; for this behavior, instruments were designed which allowed to place and play the musical instruments on the floor. We could not find any major individual preferences in terms of materials. Cardboard, wood, plastic and metal were usually well received. In general, unknown materials were met with suspicion and caution by the grey parrots. The individual preferences of the grey parrots regarding the forms of interaction with the prototypes and instruments developed have been demonstrated through different behavior such as swinging, knocking on something, pulling, tearing, destroying or nibbling. These characteristics were also taken into consideration and constantly informed the design process.

This was particularly challenging in terms of individual sound design. It was very difficult to find out more about the individual musical preferences of our group of African grey parrots. In several experiments, we could observe that music with a continuous beat was generally well received by some parrots. Certain parrots were observed to prefer the sound of the chime instrument. A precise classification of preferred musical styles such as classical music or rock music to individual parrots, as it is often postulated by informal reports of parrot owners, was not possible within the scope of this artistic research project.

It is possible and appropriate to take the individual preferences of the grey parrots into account when designing musical instruments for their auditory enrichment. The parrots showed interest in interacting with the musical instruments and used them over a long period of time. The participation of the grey parrots in the different musical settings and experiments was voluntary. In our estimation 
and also according to the opinion of the experts and animal keepers of ARGE Papageienschutz, our efforts enriched and benefited the grey parrots.

To generalize and apply our artistic research approach for auditory enrichment for other captive wild animal species we briefly recapitulate important points. It is essential to include researchers and animal experts that have species-specific knowledge and individual-specific knowledge of the involved animals. It is also necessary to find out more about the general auditory skills and individual musical preferences of the participating animals in order to better understand how they perceive, respond and communicate though sound in their artificial habitat. This can be achieved through sonic measurements of the loudness and a frequency analysis of the sound communications of the animal stakeholders and sonic preference tests as described in Section 5. We are convinced that the animal-centered design approach proposed by ACI research provide best-practice examples for designing technical mediators for auditory enrichment for captive animals [33-35]. The "SoundJam" workshop, which was held at the 5th ACI conference in 2018, offered participants an opportunity to explore different kinds of auditory enrichment for a range of animals in different environments [44]. The animal must be in the center of the design process that is informed in the best possible way be the animals' preferences, needs and personalities. To achieve this, we recommend a participatory design process that actively involve the animal as co-designers though free exploration and play.

\section{Conclusions}

We presented our efforts in designing musical instruments and interfaces for grey parrots in captivity. The project was divided into three main phases: a project review and classification [19], sonic experiments at the parrot shelter [36] and the design of musical instruments in the context of auditory enrichment for grey parrots [39].

The overview of recent musical instruments and interfaces that involve animals in the interaction and music-generation process is novel and highlights the costs and benefits of projects of this kind. It provides insights into current technologies in this field and the musical talents of animals. We examine several projects in order to arrive at a better understanding of animal-based musical projects.

We documented a series of sonic experiments conducted at ARGE Papageienschutz to develop acoustically enriched environments through the use of musical instruments. These investigations were intended to provide a better understanding of how our group of grey parrots communicate through sound, perceive and respond to auditory stimuli and possibly generate sound and music through the usage of technological devices. We identified some musical, sonic and interaction preferences of the grey parrots involved, which in turn informed the subsequent animal-centered design process.

Finally, we described the process and the methodology used to design musical instruments and interfaces for grey parrots living in captivity. The instruments were intended to offer cognitive and auditory enrichment and to intrinsically motivate the parrots to interact with musical devices. We described the animal-centered design approach towards the implementation of such technology and the possible benefits for the grey parrots. We analyzed the different forms of interaction between our group of grey parrots and the musical devices and discussed the materials and parrot toys which were the source for the instrument. We established the "Jam Session" as an artistic research approach that allowed the grey parrots to voluntarily participate as actively as possible in the design process. The six final musical instruments were presented and discussed in detail.

We have gained some insights into the complex world of musicality in animals, designing for and with animals and enrichment for grey parrots-wild animals that should never have been taken into captivity. We hope that this paper offers useful details on how to deal with grey parrots in captivity and how to improve their quality of life through auditory enrichment devices. There is still a lot to be done to provide grey parrots in captivity with a dignified living environment, and we believe there is a chance to foster relationships between grey parrots and humans by opening new creative and even artistic communication processes based on sound and music. 
We have demonstrated an artistic research approach for gaining knowledge and have shown how such an approach can have a practical and positive impact on captive animals. This project has expanded the horizon of ACI research by developing musical instruments and interfaces for animals and has also provided further contributions to design approaches in this discipline. Ultimately, we hope that our efforts have improved the living situation of the African grey parrots at the ARGE Papageienschutz parrot shelter since they certainly deserve it.

Author Contributions: Conceptualization, R.G. and M.K.; methodology, R.G. and M.K.; software, R.G. and M.K.; investigation, R.G.; writing—original draft preparation, R.G.; writing-review and editing, R.G. and M.K.; supervision, M.K.; project administration, M.K.; All authors have read and agreed to the published version of the manuscript.

Funding: This project is supported by the Austrian Science Fund FWF through the Programme for Arts-based Research (PEEK AR 349-G24).

Acknowledgments: We'd also like to thank our partners Martin Breindl, Andrea Sodomka and Norbert Math from alien productions as well as the animal keepers from ARGE Papageienschutz.

Conflicts of Interest: The authors declare no conflict of interest.

\section{References}

1. Mancini, C. Animal-Computer Interaction: A Manifesto. Interactions 2011, 18, 69-73. [CrossRef]

2. metamusic Project Web-Site. Available online: http://metamusic.at/ (accessed on 10 February 2020).

3. Mancini, C. Towards an Animal-Centred Ethics for Animal-Computer Interaction. Int. J. Hum. Comput. Stud. 2017, 98, 221-233. [CrossRef]

4. Patel, A. Seeking an Evolutionary Theory of Music; The Great Courses: Chantilly, VA, USA, 2015.

5. Honing, H. The Evolving Animal Orchestra. In Search of What Makes Us Musical; MIT Press: Cambridge, MA, USA, 2009.

6. Mingle, M.; Eppley, T.; Campbell, M.; Hall, K.; Horner, V.; de Waal, F. Chimpanzees Prefer African and Indian Music over Silence. J. Exp. Psychol. Anim. Learn. Cogn. 2014, 40, 502-505. [CrossRef] [PubMed]

7. Krohn, T.C.; Salling, B.; Hansen, A.K. How do rats respond to playing radio in the animal facility? Lab. Anim. 2011, 45, 141-144. [CrossRef] [PubMed]

8. Robbins, L.; Margulis, S.W. The effects of auditory enrichment on gorillas. Zoo Biol. 2014, 33, 197-203. [CrossRef] [PubMed]

9. Snowdon, C.T.; Teie, D.; Savage, M. Cats prefer species-appropriate music. Appl. Anim. Behav. Sci. 2015, 166, 106-111. [CrossRef]

10. Patterson-Kane, E.G.; Farnworth, M.J. Noise Exposure, Music, and Animals in the Laboratory: A Commentary Based on Laboratory Animal Refinement and Enrichment Forum (LAREF) Discussions. J. Appl. Welf. Sci. 2006, 9, 327-332. [CrossRef]

11. Wells, D.; Irwin, R. Auditory stimulation as enrichment for zoo-housed Asian elephants (Elephas maximus). Anim. Welf. 2008, 17, 335-340.

12. Hoeschele, M.; Merchant, H.; Kikuchi, Y.; Hattori, Y.; Cate, C. Searching for the origins of musicality across species. Philos. Trans. R. Soc. B 2015, 370, 20140094. [CrossRef]

13. Bottoni, L.; Massa, R.; Boero, D.L. The grey parrot as musician: An experiment with the Temperate Scale. Ethol. Ecol. Evol. 2003, 15, 133-141. [CrossRef]

14. Cate, C.T.; Spierings, M.; Hubert, J.; Honing, H. Can birds perceive rhythmic patterns? A review and experiments on a songbird and a parrot species. Front. Psychol. 2016, 7, 730. [PubMed]

15. Patel, A.; Iversen, J.; Bregman, M.; Schulz, I. Experimental Evidence for Synchronization to a Musical Beat in a Nonhuman Animal. Curr. Biol. 2009, 19, 827-830. [CrossRef] [PubMed]

16. Schachner, A.; Brady, T.; Pepperberg, I.; Hauser, M. Spontaneous motor entrainment to music in multiple vocal mimicking species. Curr. Biol. 2009, 19, 831-866. [CrossRef] [PubMed]

17. Porter, D.; Neuringer, A. Music discriminations by pigeons. J. Exp. Psychol. Anim. Behav. Process. 1984, 10, 138-148. [CrossRef]

18. Peron, F.; Hoummady, S.; Mauny, N.; Bovet, D. Touch screen and music enrichments to captive housing conditions of African grey parrots. J. Vet. Behav. 2012, 7, e13. [CrossRef] 
19. Gupfinger, R.; Kaltenbrunner, M. Animals Make Music: A Look at Non-Human Musical Expression. Multimodal Technol. Interact. 2018, 2, 51. [CrossRef]

20. Jeon, M.; Winton, R.J.; Yim, J.-B.; Bruce, C.M.; Walker, B.N. AquariumFugue: Interactive sonification for children and visually impaired audience in informal learning environments. In Proceedings of the 18th International Conference on Auditory Display (ICAD 2012), Atlanta, GA, USA, 18-21 June 2012.

21. Cordeiro, J. FuXi: A Fish-Driven Instrument for Real-Time Music Performance. In Proceedings of the 4th International Conference, EvoMUSART 2015, Copenhagen, Denmark, 8-10 April 2015.

22. Vivian, C. Submersed Songs. Available online: https://www.youtube.com/watch?v=uhTCf_311Eg (accessed on 10 February 2020).

23. Quiet Ensemble: Quintetto. Available online: https://vimeo.com/33824235 (accessed on 10 February 2020).

24. Baldan, S.; Ludovico, L.; Mauro, D. Musica Sull'Acqua. In Proceedings of the 9th Sound and Music Computing Conference (SMC2012), Copenhagen, Denmark, 12-14 July 2012.

25. Mercer-Taylor, A.; Altosaar, J. Sonification of Fish Movement Using Pitch Mesh Pairs. In Proceedings of the 15th International Conference on New Interfaces for Musical Expression (NIME'15), Baton Rouge, LA, USA, 31 May-3 June 2015.

26. Ken Rinaldo: Augmented Fish Reality. Available online: http://www.kenrinaldo.com/portfolio/augmentedfish-reality/ (accessed on 10 February 2020).

27. Chase, A. Music discriminations by carp (Cyprinus carpio). Anim. Learn. Behav. 2001, 29, 336-353. [CrossRef]

28. Ladich, F. Acoustic Communication in Fishes: Sound Production, Hearing and the Effect of Noise. Master's Thesis, Verhaltensbiologie, Universität Wien, Vienna, Austria, 2012.

29. Boursier Mougenot, C. From Here to Ear. Available online: http://www.xippas.com/artists/celeste-boursiermougenot/ (accessed on 10 February 2020).

30. Solder, D. Eine Kleine Naughtmusik: How Nefarious Nonartists Cleverly Imitate Music. Leonardo Music J. 2002, 12, 53-58. [CrossRef]

31. Solder, D. Kinship with Animals: Thai Elephant Orchestra. Available online: http://davesoldier.com/articles/ DaveKinship\%20with\%20Animals.pdf (accessed on 30 April 2020).

32. Smithsonian Magazine: Otters Play a Piano at the National Zoo. Available online: http:// www.smithsonianmag.com/videos/category/science/otters-play-a-piano-at-the-national-zoo/ (accessed on 20 April 2018).

33. French, F.; Mancini, C.; Sharp, H. High tech cognitive and acoustic enrichment for captive elephants. J. Neurosci. Methods 2018, 300, 173-183. [CrossRef]

34. French, F.; Mancini, C.; Sharp, H. Designing Interactive Toys for Elephants. In Proceedings of the 2015 Annual Symposium on Computer-Human Interaction in Play-CHI PLAY'15, London, UK, 5-7 October 2015.

35. Pons, P.; Carter, M.; Jaén, J. Sound to your objects: A novel design approach to evaluate orangutans' interest in sound-based stimuli. In Proceedings of the 3rd International Conference on Animal-Computer Interaction, Milton Keynes, UK, 15-17 November 2016.

36. Gupfinger, R.; Kaltenbrunner, M. Sonic Experiments with Grey Parrots: A Report on Testing the Auditory Skills and Musical Preferences of Grey Parrots in Captivity. In Proceedings of the Fourth International Conference on Animal-Computer Interaction (ACI 2017), Milton Keynes, UK, 21-23 November 2017; pp. 3:1-3:6.

37. Lepperhoff, L. Graupapageien; Eugen Ulmer: Stuttgart, Germany, 2007.

38. Beason, R.C. What Can Birds Hear? USDA National Wildlife Research Center-Staff Publications: Fort Collins, CO, USA, 2004.

39. Gupfinger, R.; Kaltenbrunner, M. Animal-Centered Sonic Interaction Design: Musical Instruments and Interfaces for Grey Parrots. In Proceedings of the 6th International Conference on Animal-Computer Interaction (ACI 2019), Haifa, Israel, 12-14 November 2019.

40. Chisik, Y.; Mancini, C. P for Politics D for Dialogue: Reflections on Participatory Design with Children and Animals. In Proceedings of the Sixth International Conference on Animal-Computer Interaction (ACI'19), Haifa, Israel, 12-14 November 2019; Association for Computing Machinery: New York, NY, USA, 2019.

41. Hirskyj-Douglas, I.; Pons, P.; Read, J.; Jaen, J. Seven Years after the Manifesto: Literature Review and Research Directions for Technologies in Animal Computer Interaction. Multimodal Technol. Interact. 2018, 2, 30. [CrossRef] 
42. Pepperberg, I.M. Cognitive and communicative abilities of Grey parrots. Appl. Anim. Behav. Sci. 2006, 100, 77-86. [CrossRef]

43. Pepperberg, I.M. Vocal learning in Grey parrots: A brief review of perception, production, and cross-species comparisons. Brain Lang. 2010, 115, 81-91. [CrossRef] [PubMed]

44. French, F.; Gupfinger, R.; Kendrick, P. SoundJam: Acoustic Design for Auditory Enrichment. In Proceedings of the 5th International Conference on Animal-Computer Interaction (ACI 2018), Atlanta, GA, USA, 4-6 December 2018. article distributed under the terms and conditions of the Creative Commons Attribution (CC BY) license (http://creativecommons.org/licenses/by/4.0/). 